\title{
Erratum to: Research Ethics in the Assessment of PhD Theses: Footprint or Footnote?
}

\author{
Allyson Holbrook ${ }^{1} \cdot$ Kerry Dally $^{1} \cdot$ Carol Avery $^{1}$. \\ Terry Lovat ${ }^{1} \cdot$ Hedy Fairbairn ${ }^{1}$
}

Published online: 3 August 2017

(C) Springer Science+Business Media B.V. 2017

\section{Erratum to: J Acad Ethics (2016) \\ DOI 10.1007/s10805-017-9276-Z}

Due to an oversight by the Publisher during the typesetting stage, an uncorrected version of the paper was published. The revisions submitted by the author had not been carried out. The paper has now been updated and includes all the author's corrections.

The Publisher apologizes for this error.

The online version of the original article can be found at http://dx.doi.org/10.1007/s10805-017-9276-Z

Allyson Holbrook

Allyson.Holbrook@newcastle.edu.au

Kerry Dally

Kerry.Dally@newcastle.edu.au

Carol Avery

Carol.Avery@uon.edu.au

Terry Lovat

Terry.Lovat@newcastle.edu.au

Hedy Fairbairn

Hedy.Fairbairn@newcastle.edu.au

1 Centre for the Study of Research Training and Impact (SORTI), Faculty of Education \& Arts, The University of Newcastle, University Drive, Callaghan, NSW 2304, Australia 